\title{
Effect of Guide Vane in Ring Groove Arrangement for a Small Turbocharger
}

\author{
Daisaku Sakaguchi ${ }^{1}$, Keiichi Nagoshi ${ }^{1}$, Motoki Tanimura ${ }^{1}$, \\ Masahiro Ishida ${ }^{1}$ and Hironobu Ueki ${ }^{2}$ \\ ${ }^{1}$ Graduate School of Science and Technology, Nagasaki University \\ 1-14 Bunkyo-machi Nagasaki 852-8521 JAPAN, daisaku@ nagasaki-u.ac.jp \\ ${ }^{2}$ Department of Mechanical Systems Engineering, Nagasaki University \\ 1-14 Bunkyo-machi Nagasaki 852-8521 JAPAN
}

\begin{abstract}
A high-pressure ratio and a wide operating range are highly required for a turbocharger in diesel engines. Ring groove arrangement is effective for flow range enhancement of centrifugal compressors. Two ring grooves on the suction pipe and the shroud casing wall are connected by means of the annular passage, and the stable recirculation flow is formed at small flow rates from the downstream groove toward the upstream groove through the annular bypass. It is well known that the ring groove arrangement shows the following two merits; (1) the formation of recirculation flow removes the low energy fluid around the downstream groove located near the splitter blade leading edge, (2) the flow incidence can be reduced because the recirculation flow merges again with the incoming main flow upstream of the impeller inlet. In the present study, the ring groove arrangement was applied to the high speed centrifugal compressor, in addition, in order to suppress too large pre-whirl due to the recirculation flow, the effects of guide vane installed in the annular passage and the ring groove configuration on the pre-whirl were analyzed numerically. The numerical flow analysis was carried out by using the commercial code produced by ANSYS-CFX. The simulation results show the multi-ring grooves are fairly effective in combination with the suitable configuration of guide vanes for improvement in the inlet velocity distortion.
\end{abstract}

Keywords: Turbocharger, Centrifugal Compressor, Flow Range Enhancement, Ring Groove Arrangement, Guide Vane

\section{Introduction}

Adoption of a clean diesel engine is one of the solutions for successful reduction of carbon dioxide exhausted from passenger vehicles. The key technology for a clean diesel engine is dependent upon a high efficiency turbocharger, which improves the incylinder combustion under sufficient oxygen condition. In recent diesel engines with high pressure ratio turbocharger as well as high EGR (Exhaust Gas Recirculation) ratio [1], the centrifugal compressor is often operated near the surge line, which varies with the rotational speed. As for a centrifugal compressor for turbocharger, a trade-off between a high-pressure ratio and a wide operating range is a technical issue. The unstable flow occurring at small flow rates is due to flow separation in the impeller and diffuser especially on the shroud wall near the inlet throat, finally resulting in surge.

A casing treatment for flow range enhancement in a centrifugal compressor was investigated firstly by Fisher [2], who showed experimentally in the turbocharger for a marine diesel engine that the availability of the recirculation flow formation by means of the casing treatment. Recently, the internal flow of the recirculation device is simulated by CFD code, the research group from ABB [3] developed the inducer casing bleed system which is one kind of recirculation type casing treatment for small turbochargers. The transient motion of the internal flow was simulated numerically and the compressor characteristics were compared with the experimental results under the several flow rate conditions. The research group from TOYOTA [4] also developed the self-recirculation type casing treatment for turbochargers. The numerical and experimental results showed that the combination with the variable inlet guide vane was very effective for uniformalizing the inlet velocity distortion. The research group from IHI [5] showed the advantage of the guide vane inside of the recirculation flow channel. The experimental and numerical results showed that the pressure ratio and recirculation flow rate could be improved by suppression of the circumferential component of velocity of the recirculation flow. 
Authors [6] also discussed with respect to advantages of the recirculation device showing the numerical simulation results as well as the experimental results in a low speed centrifugal impeller. By connecting two grooves with the annular passage on the shroud casing wall, the stable recirculation flow could be formed at small flow rates. However, when the ring groove arrangement is applied to the high speed centrifugal compressor, the velocity distribution at the impeller inlet is fairly distorted especially at the shroud side because of a large circumferential component of velocity of the recirculation flow. Too large pre-whirl reduces the pressure rise in the impeller, and results in a smaller recirculation flow rate. In the present study, in order to suppress too large prewhirl at the shroud side of impeller inlet, guide vanes were installed in the annular passage of the recirculation device, and the effects of guide vanes and grooves on the flow in the impeller are analyzed numerically by ANSYS-CFX.

\section{Numerical Simulation}

The flow was simulated for the model impeller of an automotive turbocharger. The meridional section of the tested impeller is shown in Fig.1-(a). The un-shrouded impeller has six main blades and six splitter blades, the total number of blade is twelve. The exit and inlet radius of the impeller are 25.5 and $19.2 \mathrm{~mm}$ respectively. The simulation was carried out at a constant impeller rotational speed of $120,000 \mathrm{rpm}$ which corresponds to the inlet tip Mach number of $\mathrm{Mt}=0.695$, and under the condition without scroll casing for simplicity. The inlet blade angles are 37 and 68 degrees at the blade root and at the blade tip respectively from the circumferential direction. The exit blade angle is 45 degrees and the exit blade height is $4.5 \mathrm{~mm}$. The clearance between the impeller blade tip and the shroud wall is $0.3 \mathrm{~mm}$. The vaneless diffuser is located at the downstream of the impeller with the exit radius of $\mathrm{R}=2.0$. The pinch diffuser was applied until the radius ratio of $\mathrm{R}=1.1$ in order to suppress the reverse flow on the shroud casing wall. With respect to the ring grooves, the upstream groove is placed at $18 \mathrm{~mm}$ upstream of the impeller inlet with the width of $5 \mathrm{~mm}$. The downstream groove is placed near the splitter blade leading edge with 2 mm width. The two grooves are connected by the annular passage with $5 \mathrm{~mm}$ height. The three dimensional turbulent flow was calculated by using the commercial CFD code ANSYS-CFX together with the $k-\omega$ based SST (Share Stress Transport) turbulence model. In the calculation, one of the impeller passages with the main and the splitter blade is selected. The impeller passage is referenced to the relative frame. The computational mesh on the meridional plane is shown in Fig.1-(b). The total number of element for the impeller passage is about 1.1 million with hexahedral mesh. In order to have a smooth mesh distribution, the O-grid was applied around the blade. The node number inside of the tip clearance is 13 . Two grooves and the annular passage are referenced to the absolute frame. The total number of elements for the groove passage is about 320 thousand with tetrahedral mesh to achieve the smooth mesh with complex geometry. The multi-frame of references consisting of the rotating domain of the impeller section and the stationary domain of the ring groove arrangement section were adopted. Interfaces between two domains are coupled with the GGI (General Grid Interface) connection of ANSYS-CFX feature. The discharged mass flow rate was set at the diffuser exit boundary, and the total pressure and the total temperature were set at the inlet boundary of the suction pipe.

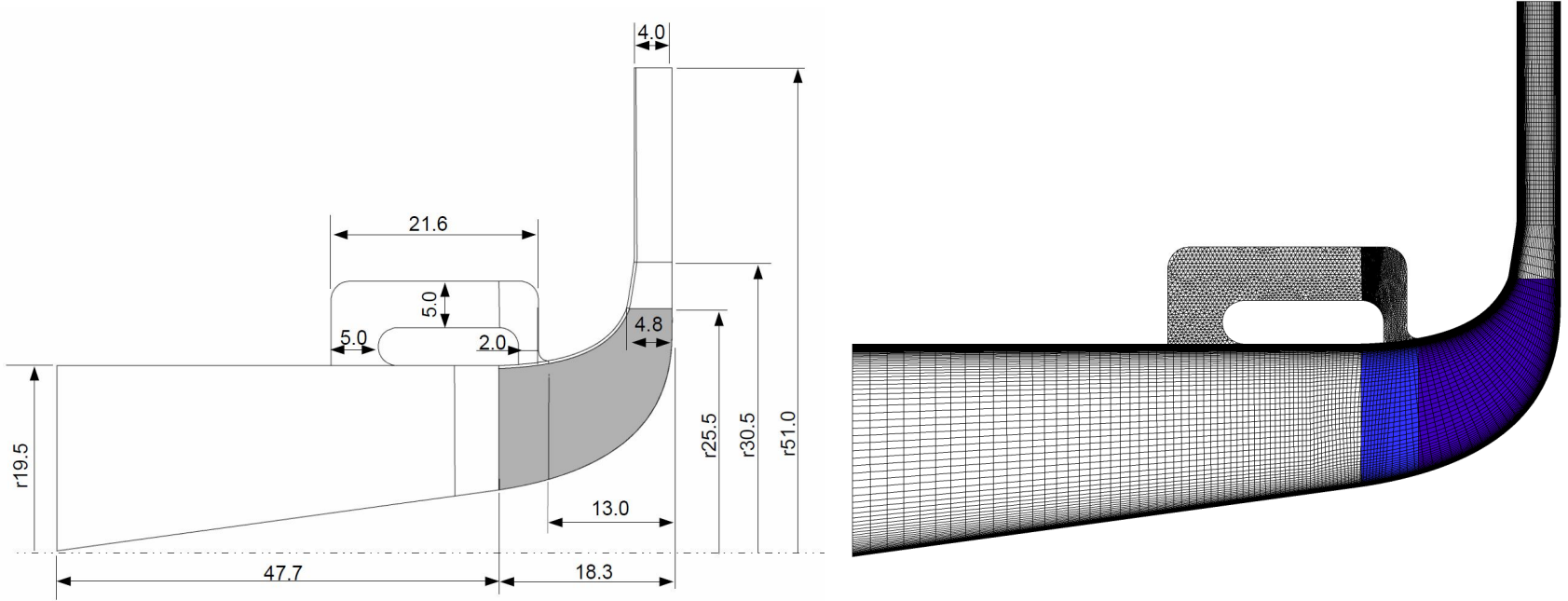

(a) Configuration with ring groove arrangement

(b) Computational grid

Fig. 1 Meridional section of the test compressor 


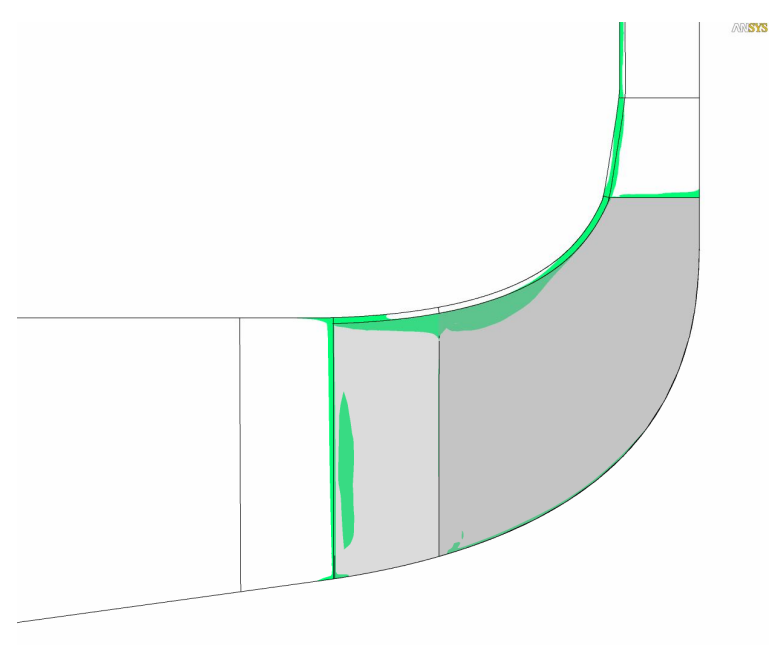

(a) w/o groove

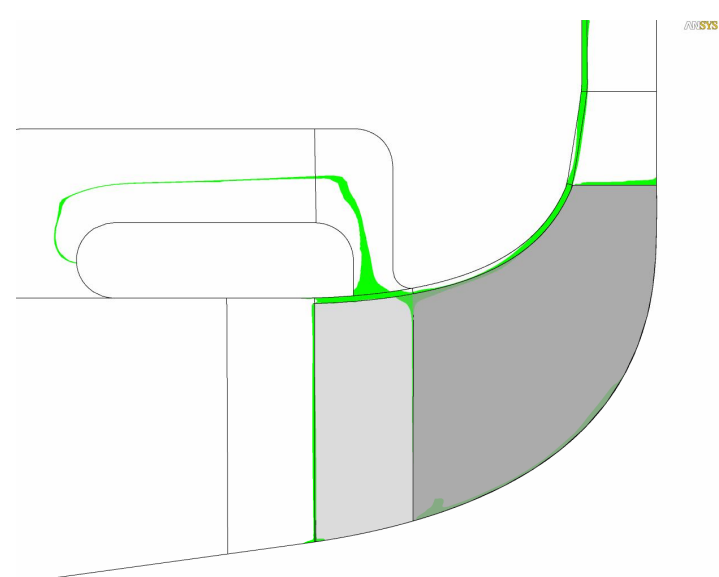

(b) with groove

Fig.2 Projection of the three dimensional reverse flow zone on the meridional plane $\left(\mathrm{G} / \mathrm{G}^{*}=0.382\right)$

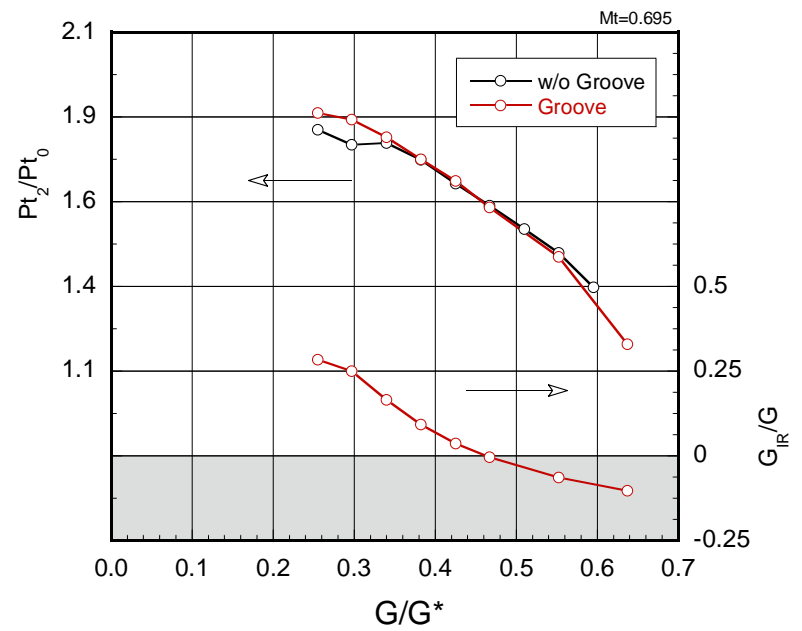

Fig.3 Total pressure ratio and recirculation flow rate

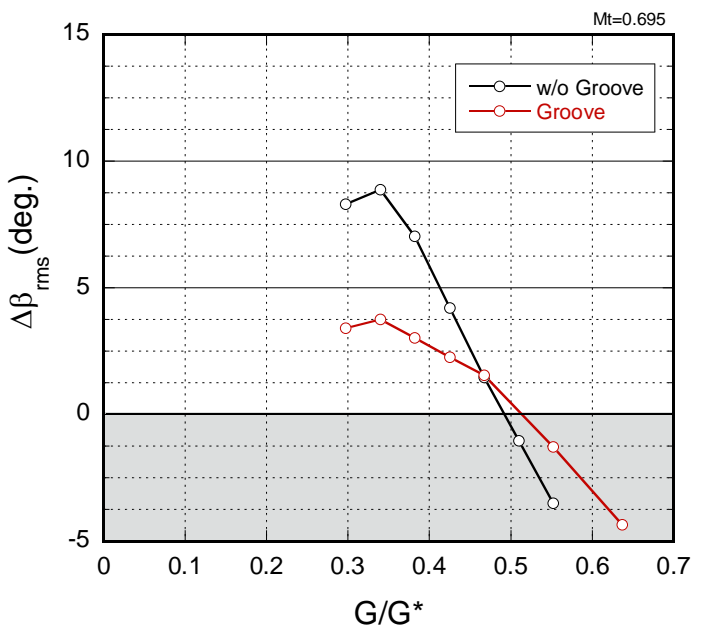

Fig.4 Flow incidence at root mean square radius

\section{Results and Discussion}

\subsection{Effect of Ring Groove Arrangement}

Three dimensional flow separation zone was projected to the meridional plane as shown in Fig. 2 in the case of the mass flow rate of $\mathrm{G} / \mathrm{G}^{*}=0.382$, in which $\mathrm{G}^{*}$ is the choke flow rate at the inlet suction pipe. In the case without the ring groove arrangement shown in Fig.2-(a), the reverse flow zone is seen on the shroud casing wall near the splitter blade leading and the leading edge separation of the main blade. In order to improve the surge margin, it is very important to suppress these two separation zones.[6] In the case with ring groove arrangement shown in Fig.2(b), the reverse flow region on the shroud casing near the splitter blade leading is sucked into the groove. The sucked flow merges again with the incoming main flow at upstream of the impeller inlet and the leading edge separation was reduced successfully. 


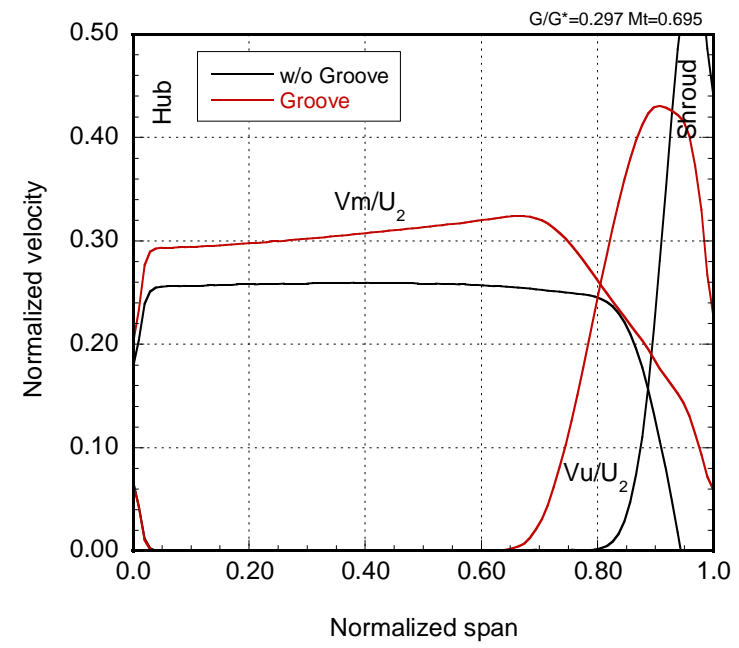

(a) Normalized velocity

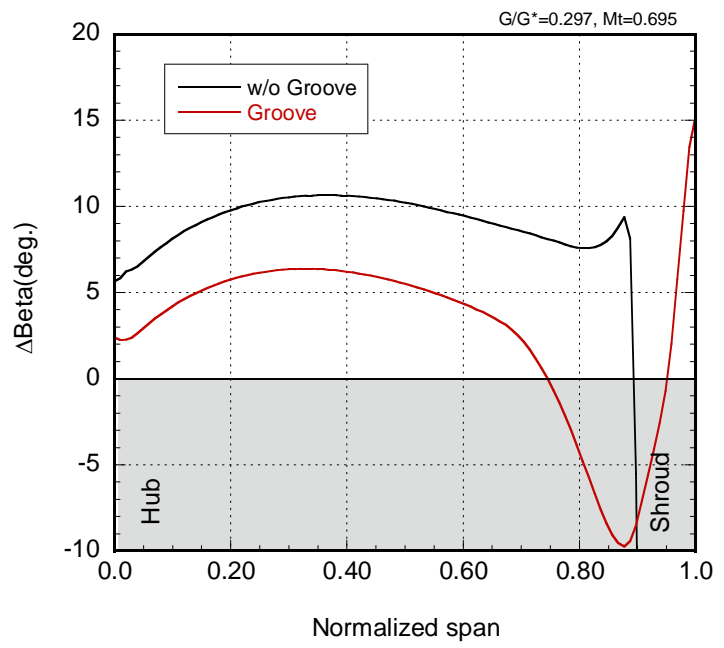

(b) Flow incidence

Fig.5 Normalized velocity and flow incidence distribution at impeller inlet $\left(\mathrm{G} / \mathrm{G}^{*}=0.297\right)$

The total pressure ratio $\mathrm{PT}_{2} / \mathrm{PT}_{0}$ and the recirculation flow rate $\mathrm{G}_{\mathrm{IR}} / \mathrm{G}$ is shown in Fig.3 as a function of discharged flow rate. In the case without the ring groove arrangement, the total pressure ratio drops near $\mathrm{G} / \mathrm{G}^{*}=0.3$. In the case of the ring groove arrangement, the pressure drop disappears at small flow rates. The recirculation flow rate increases as the flow rate decreases. The positive value of the recirculation flow rate $\mathrm{G}_{\mathrm{IR}} / \mathrm{G}^{*}$ indicates that the flow direction inside of the annular passage is from the downstream groove to the upstream groove. The maximum recirculation flow rate reaches to $25 \%$ in this case.

Figure 4 shows the flow incidence at the root mean square radius of the impeller inlet. The flow incidence increases almost linearly as the flow rate decreases. According to the previous study [6], the critical flow incidence for the high specific speed centrifugal impeller was about 9.0 degrees. It is important not to exceed the critical flow incidence for suppression of the unstable flow at small flow rates. In the case of the ring groove arrangement, the flow incidence decreased around 5 degrees at small flow rates. The change of the flow incidence due to the discharged flow becomes small by applying the ring groove arrangement. The small flow incidence is the advantage of the ring groove arrangement which guarantees the stable operation in small flow rates.

The distributions of velocity components and flow incidence at the impeller inlet are shown in Fig.5 in the case of the small mass flow rate of $\mathrm{G} / \mathrm{G}^{*}=0.297$. The meridional component of velocity $\mathrm{V}_{\mathrm{m}}$ and the circumferential component of the absolute velocity $V_{u}$ are normalized by the impeller tip speed $U_{2}$. In the case without the ring groove arrangement, the reverse flow zone indicated by the negative value of $\mathrm{V}_{\mathrm{m}}$ is seen at the shroud side. In the reverse flow zone, the circumferential component of velocity is extremely high. On the other hand, in the case with the ring groove arrangement, the reverse flow zone disappears at the shroud side, and the meridional component of velocity is increased in the whole span region. The increment of the meridional velocity is based on the recirculation flow from the upstream groove and a large circumferential velocity is extended from the tip to the $60 \%$ span. Suitable pre-whirl is acceptable to suppress the leading edge separation, however, too large pre-whirl causes negative flow incidence at the shroud side such as shown in Fig.5-(b). The negative flow incidence results in decrease of the pressure rise along the shroud and results in decrease of the recirculation flow rate. It is clear that, in order to obtain a flat inlet velocity distribution, the circumferential component of velocity due to the recirculation flow should be suppressed.

\subsection{Effect of Guide Vane}

In order to suppress the circumferential component velocity of the recirculation flow, the guide vane was installed inside of the annular passage as shown in Fig.6. The straight shape 18 guide vanes were installed at middle of the annular passage. The reverse flow zone is shown in Fig.7 at the flow rate of $\mathrm{G} / \mathrm{G}^{*}=0.297$. By applying the guide vane, the reverse flow zone on the shroud casing wall is sucked out. Figure 8 shows the velocity and flow incidence distribution at impeller inlet. By applying the guide vane, the circumferential velocity is suppressed successfully and the meridional velocity increased except in shroud side. The increased meridional velocity indicates the increased recirculation flow rate. However, the flow incidence shows large positive value at shroud side in the case of the guide vane. The recirculation flow from the upstream groove does not go toward the shroud side of the impeller inlet because of the less centrifugal force. In order to obtain the flow incidence distribution as flat as possible, it is important to supply the mass flow at shroud side of the impeller inlet. 


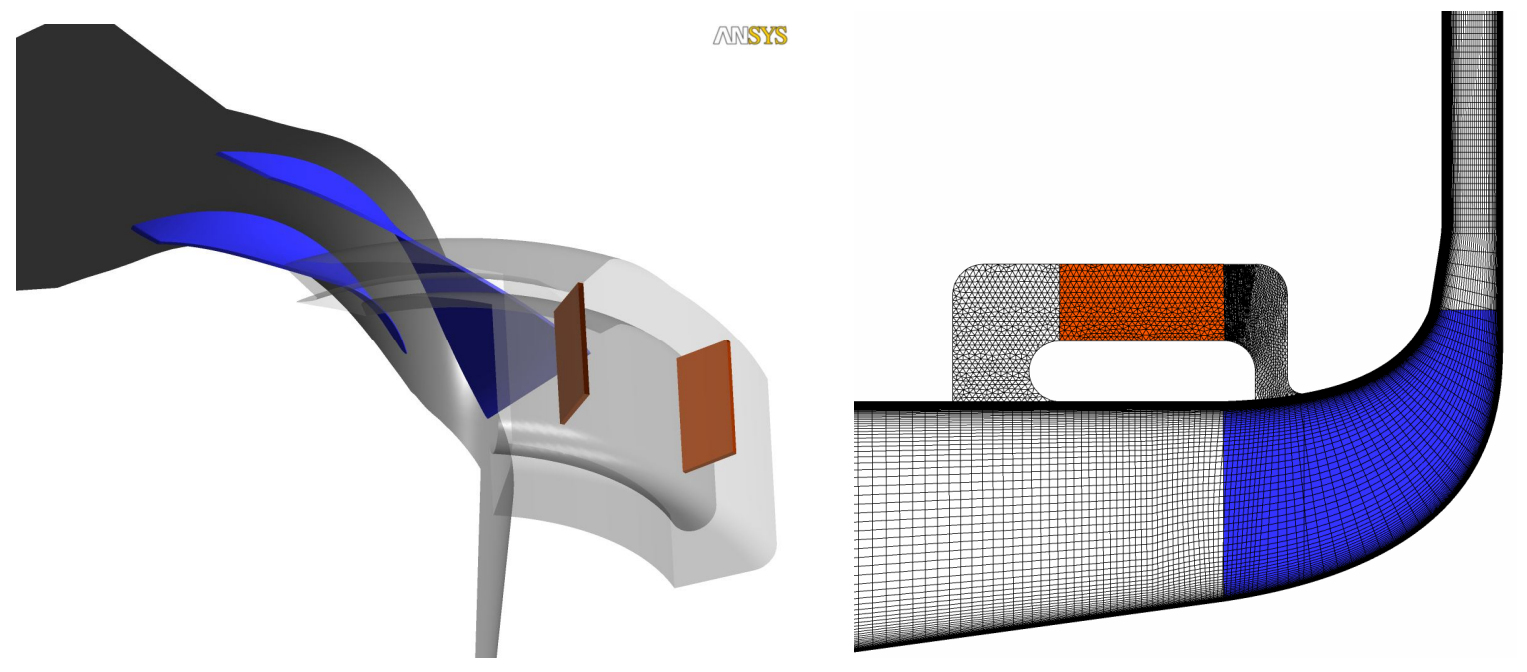

Fig.6 Guide vane inside of the ring groove arrangement

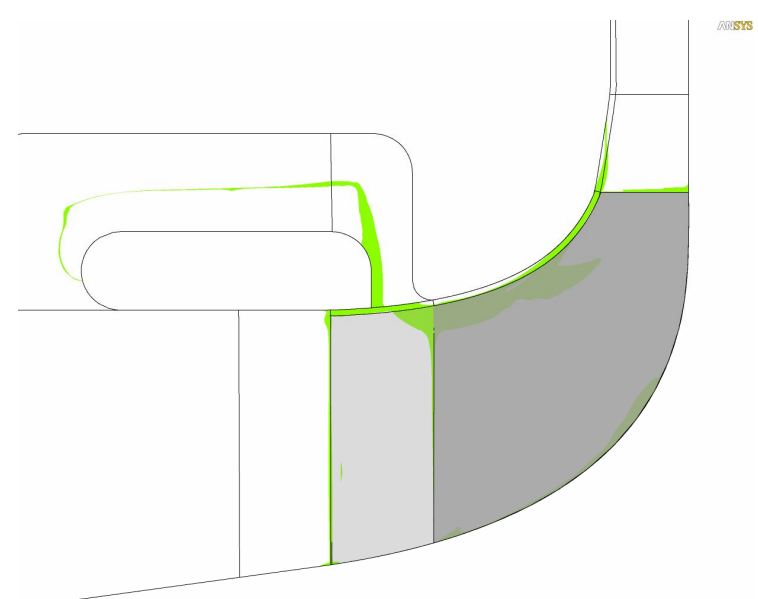

(b) w/o guide vane

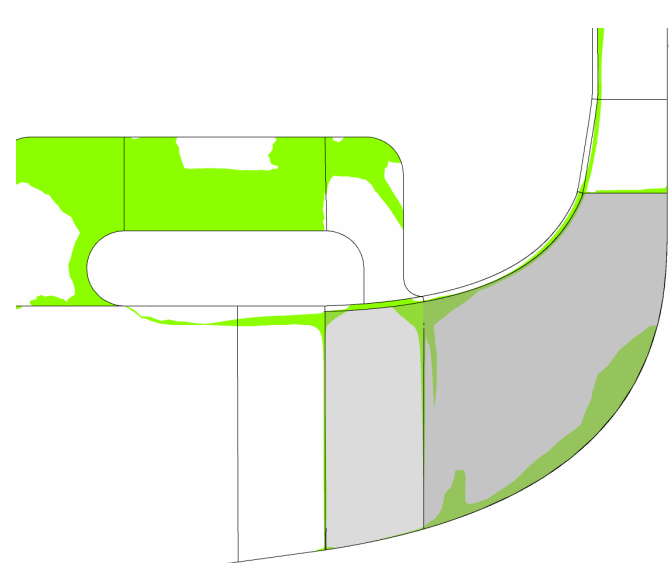

(b) with guide vane

Fig.7 Projection of the three dimensional reverse flow zone on the meridional plane $\left(\mathrm{G} / \mathrm{G}^{*}=0.297\right)$

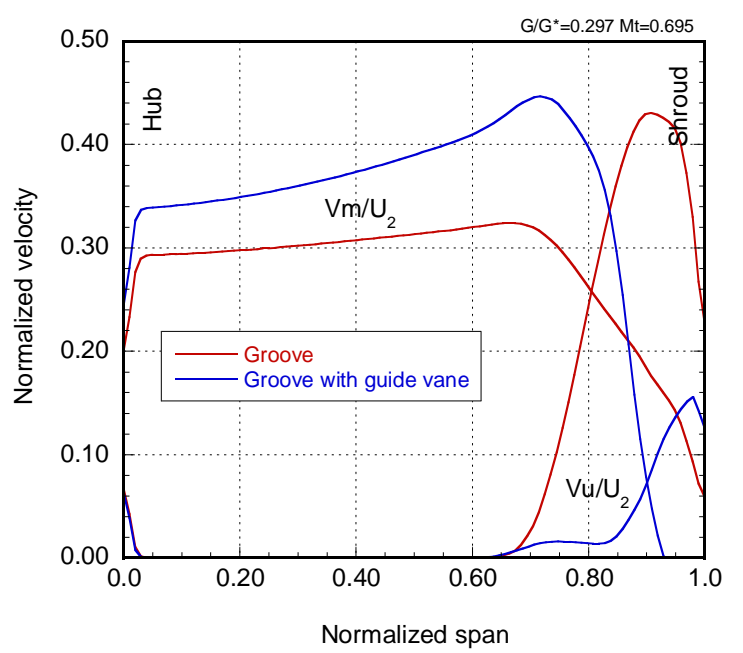

(b) Normalized velocity

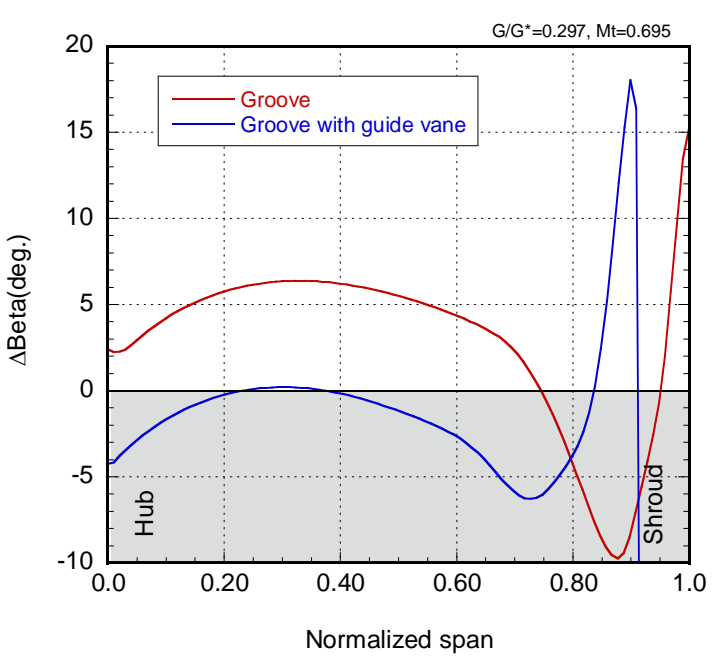

(b) Flow incidence

Fig.8 Normalized velocity and flow incidence distribution at impeller inlet (with guide vane, G/G*=0.297) 

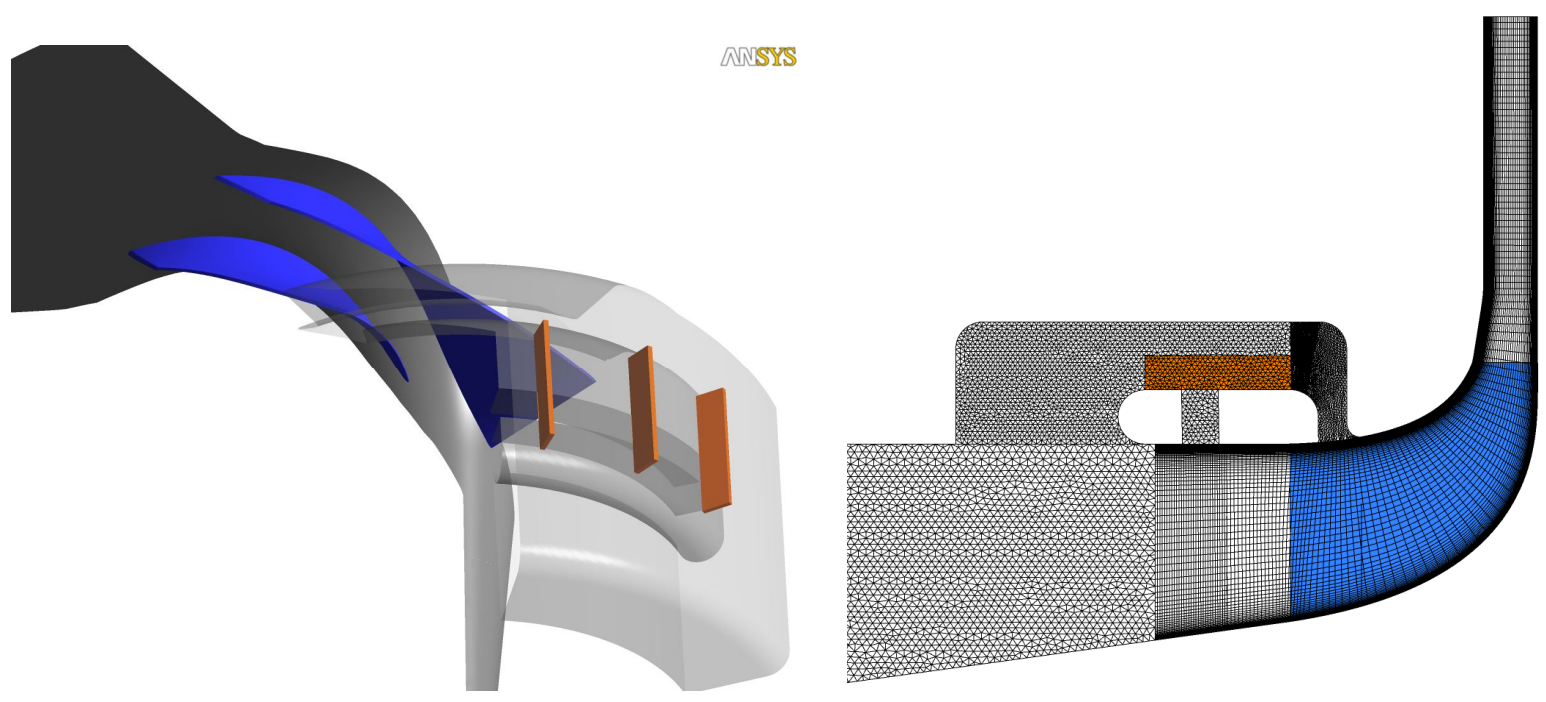

Fig.9 Guide vane with middle groove

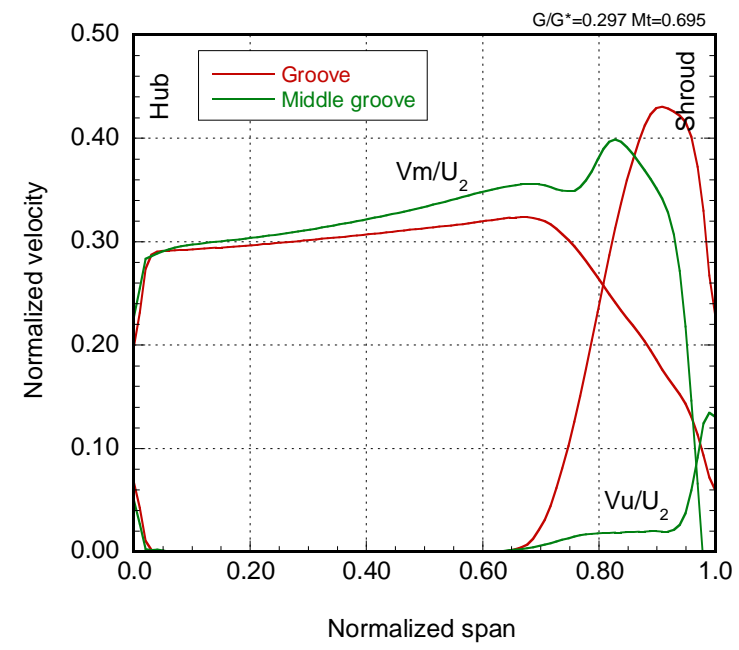

(a) Normalized velocity

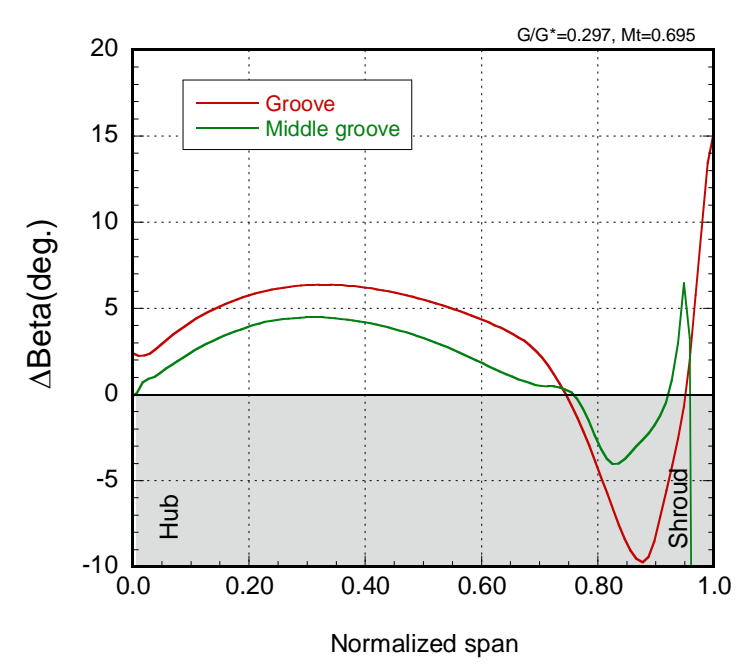

(b) Flow incidence

Fig.10 Normalized velocity and flow incidence distribution at impeller inlet $\left(\mathrm{G} / \mathrm{G}^{*}=0.297\right)$

\subsection{Combination of Guide Vane and Multi-Grooves}

The guide vane is very effective for increasing the recirculation flow rate, however, the velocity distortion at the impeller inlet is still too large. In order to obtain the incidence distribution as uniform as possible, the mass flow rate at the shroud side has to increase. Figure 9 shows a new concept of the ring groove arrangement. The enlarged upstream groove was applied aiming at reducing the jet flow discharged from the upstream groove. The middle groove between the upstream and downstream grooves was newly appended to supply the mass flow at the shroud side, in addition, the half height guide vane was also applied to control the mass flow rate. The velocity and flow incidence distribution at the impeller inlet is shown in Fig.10. The recirculation flow from the middle groove increases the meridional velocity at the shroud side, as a result, the flow incidence distortion is improved.

The total pressure ratio $\mathrm{PT}_{2} / \mathrm{PT}_{0}$ and the recirculation flow rate $\mathrm{G}_{\mathrm{IR}} / \mathrm{G}$ as a function of the discharged flow rate is shown in Fig11. In the case with the middle groove, the recirculation flow rate was improved at small discharged flow rate condition, the maximum recirculation flow rate reached to $46 \%$. It is noticed that the deviation of the flow incidence becomes smaller by applying the middle groove as shown in Figure 12. The flow incidence at the root mean square radius at the impeller inlet is smaller than 2 degrees in whole flow rate range. 


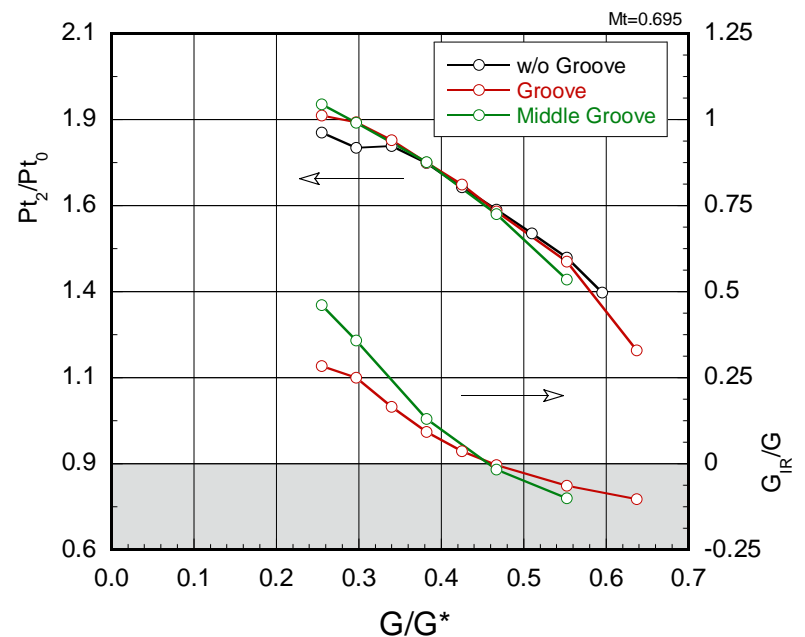

Fig.11 Total pressure ratio and recirculation flow rate

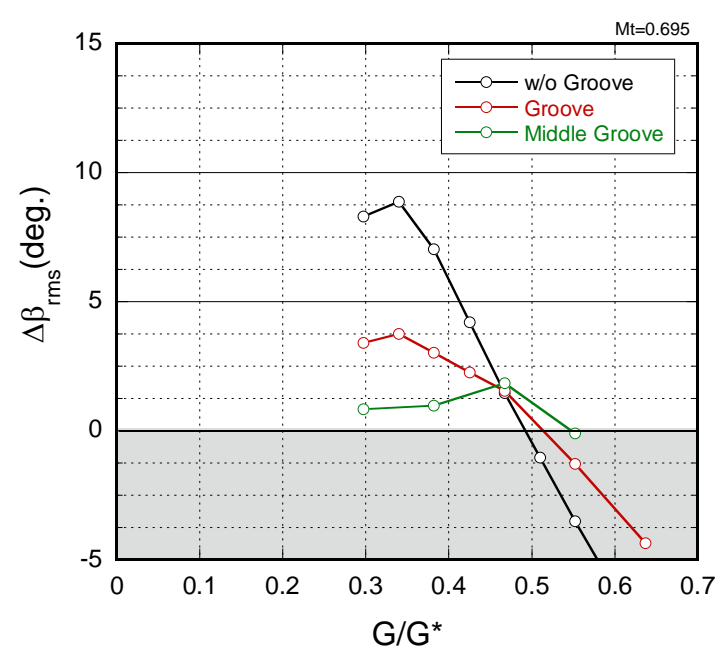

Fig.12 Flow incidence at root mean square radius

\section{Conclusion}

In order to improve the surge margin of a centrifugal compressor for automotive turbochargers, the effect of the ring groove arrangement with the guide vane was investigated by numerical simulation. The recirculation flow rate, the flow incidence and the velocity distributions at the impeller inlet are investigated with or without the guide vane inside of the ring groove arrangement. The following concluding remarks are obtained,

(1) Too large pre-whirl due to the recirculation flow results in a marked decrease of the flow incidence at the shroud side.

(2) By applying the guide vane inside the annular passage, the circumferential component of the velocity is suppressed, however, the recirculation flow from the upstream groove does not go toward the shroud side of the impeller inlet. As a result, the flow incidence shows large positive value at shroud side in the case with the guide vane.

(3) The multi-groove with the half height guide vane is effective for increasing the mass flow at the shroud side of the impeller inlet. The flow incidence distortion could be improved successfully in whole flow rate range.

\section{Acknowledgments}

The computational simulation was performed by the cluster computer system of graduate school of science and technology in Nagasaki University. This research work was financially supported by Harada memorial foundation and Japan Science and Technology Agency.

\section{Nomenclature}

$G$

$G^{*}$

$G_{I R}$

$M t$

$P_{T 0}$

$P_{T 2}$

$R$

$r$
Discharged mass flow rate $[\mathrm{kg} / \mathrm{s}]$

Choke mass flow rate at inlet suction pipe $[\mathrm{kg} / \mathrm{s}]$

Mass flow rate of inlet recirculation $[\mathrm{kg} / \mathrm{s}$ ]

Inducer tip mach number $\left[=(\mathrm{kRT})^{\wedge} 0.5\right]$

Total pressure at impeller inlet $[\mathrm{Pa}]$

Total pressure at impeller exit $[\mathrm{Pa}]$

Radius ratio (r/r2)

Radius
$U 2$

$V_{m}$

$V_{u}$

$\Delta \beta$

rms

0

1

2
Tip speed at impeller exit $[\mathrm{m} / \mathrm{s}]$

Meridional component of abs. velocity $[\mathrm{m} / \mathrm{s}]$

Tangential component of abs. velocity $[\mathrm{m} / \mathrm{s}]$

Flow incidence [deg.]

Root mean square

Inlet boundary of the suction pipe

Impeller inlet

Impeller exit 


\section{References}

[1] Uchida, N., 2005, "Required Turbocharger Specifications for Future Commercial Diesel Engines", Journal of the Gas Turbine Society of Japan, Vol. 33, No.4, pp.295-300(in Japanese)

[2] Fisher, F. B., 1988, "Application of Map Width Enhancement Devices to Turbocharger Compressor Stages", SAE Paper No.880794

[3] Dickmann, H-P., etc., 2006, "Unsteady Flow in a Turbocharger Centrifugal Compressor: Three-Dimensional Computational Fluid Dynamics Simulation and Numerical and Experimental Analysis of Impeller Blade Vibration ", Transaction of the ASME, Journal of Turbomachinery, Vol.128, pp.455-465

[4] Iwakiri, Y., Uchida, H., 2006, "Numerical Fluid Analysis of a Variable Geometry Compressor for Use in a Turbocharger", R\&D Review of Toyota CRDL Vol.41 No.3, pp.15-21

[5] Goto, S., Yamaguchi, S., Nakao, H., Yamaguchi, H., and Nakamura, F., 2003, "Study on Wide Flow Range Centrifugal Compressor with Casing treatment for Turbocharger", Turbomachinery, vol.31, No.8, pp.482-486 (in Japanese)

[6] Ishida, M., Sakaguchi, D., Ueki, H., 2005, "Optimization of Inlet Ring Groove Arrangement for Suppression of Unstable Flow in a Centrifugal Impeller”, ASME Paper No. GT2005-68675 